\title{
Processos projetuais emergentes: A utilização de Design Digital e Prototipagem Rápida aplicados em Extensão Universitária
}

\author{
Emerging designing processes: The use of Digital Design and Rapid Prototyping applied in University Extension \\ - Denivaldo Pereira Leite \\ Centro Universitário Belas Artes de São Paulo, \\ Brazil \\ denivaldo.leite@belasartes.br \\ - Júlia Tenuta Martins \\ Centro Universitário Belas Artes de São Paulo, \\ Brazil \\ tenuta.julia@gmail.com
}

\begin{abstract}
This paper is about the experience to show the possibilities of the Algorithm Aided Design to a community of students and Professors that actually uses Computed Aided Design, but just for drawings, not for a full digital process. This community is hosted at Belas Artes de São Paulo, who in February of 2015, opened up its first Digital Fabrication Laboratory, but people there didn't have a good idea of what it could be, beyond scale models. It shows that the new theory that supports new digital paradigms in architecture and design was the job acquired for a research group.
\end{abstract}

Keywords: Algorithm Aided Design, Education, Digital Fabrication, Catenary Based Geometries, Musgum

\section{Introdução}

O Centro Universitário Belas Artes de São Paulo inaugurou em Fevereiro de 2015 seu primeiro Laboratório de Fabricação Digital e Prototipagem Rápida e uma série de questões vieram à tona imediatamente. Talvez, dentre as inúmeras perguntas, a mais importante seja: de que maneira iniciar um trabalho de difusão das possibilidades dos processos digitais de trabalho, dentro da própria escola, uma vezqueocorpodocente, econsequentemente discente, ainda são adeptos dos meios analógicos de projetar? Desta forma, a referida instituição, tem incentivado a organização de palestras com nomes importantes ligados ao Design Digital, workshops e, entre outras ações, ressaltamos aqui o estabelecimento de uma atividade extracurricular, posicionada como Extensão Universitária, intitulada "Processos Projetuais Emergentes: Design e Fabricação Digital para a construção de um abrigo responsivo".

De acordo com o que Rivka Oxman cita em seu artigo "Theory and design in the first digital age", de 2006, que além de ressaltar modelos paradigmáticos de processos digitais de trabalho, o qual o grupo dedica-se a desenvolver seguindo o modelo de generative models e performance models, tomou-se também o objetivo principal desta atividade de extensão, que é criar um ambiente de reflexão na prática, onde as ferramentas digitais de design e fabricação e as relações que se criam entre o designer ou arquiteto, e seu produto final, assumam caráter de análise e comparação com os processos tradicionais utilizados tanto no curso de Arquitetura e Urbanismo como Design
Industrial. Os produtos desta atividade servirão de base para divulgação das potencialidades dos processos digitais de trabalho, dentro da própria escola e, com o envolvimento de professores e alunos, contribuir para a criação de bases para a futura e gradual modificação da base curricular dos programas dos cursos mencionados, adequando-os a tais realidades contemporâneas.

\section{Metodologia}

O processo metodológico para esta atividade foi dividido em três frentes de trabalho que se iniciaram um semestre antes da inauguração efetiva do Laboratório de Fabricação Digital e Prototipagem Rápida e que ocorreram simultaneamente: A divulgação do conteúdo teórico; treinamento dos alunos na utilização de softwares específicos, uma vez que na instituição as aulas de informática aplicada não estavam atualizadas às novas tecnologias e enfocavam a utilização de tais técnicas exclusivamente para representação; e aplicação dos conhecimentos adquiridos resolvendo o problema de projeto e fabricação de um abrigo responsivo.

Frente 01: Tutoriais e ferramentas de programação: 0 Grasshopper como atividade complementar.

O uso de sistemas de desenho assistido por computador encontra-se assimilado pela maioria dos professores e alunos de nossa instituição, porém nosso corpo discente e docente desconhecia que designers e arquitetos vêm, ao longo das 
últimas décadas, tornando-se desenvolvedores de suas próprias ferramentas, através da utilização de programação ou script. Como mencionado, utiliza-se em nossa escola os meios digitais apenas para representação de projetos.

Tivemos que induzir, em nossa comunidade, as pessoas a raciocinarem a partir de algumas perguntas básicas: Mas para que utilizarmos tais técnicas? Por que programarmos? Qual a motivação para modificar o processo de trabalho? Apresentamos o assunto programação a partir da preeminência do script como elemento universal nas grandes obras publicadas nos últimos 20 anos, mesmo que haja uma ausência desta disciplina nos currículos das faculdades de arquitetura e design. Em segundo lugar, destacamos as inovações nas áreas de software e hardware, que permitiram interfaces mais amigáveis e equipamentos mais potentes, que rodam programações mais complexas e as consequentes saídas para fabricação digital que tais técnicas possibilitaram.

Como se sabe, o script, ou programação, possibilita que o designer adapte, customize ou reconfigure por completo o software de desenho assistido por computador, de acordo com suas predileções e modos de trabalho. Quando o designer ou arquiteto utiliza o script para modificar suas ferramentas isso não somente potencializa suas tarefas repetitivas, uma vez que pode, por exemplo, combinar bibliotecas de objetos que deveriam ser posicionadas uma a uma, a um algoritmo que posicione inteligentemente toda a biblioteca seguindo parâmetros pré-estabelecidos em uma programação prévia, planejada pelo próprio arquiteto, seguindo questões relativas ao projeto da mais variada ordem, desde elementos relacionados a desempenho lumínico, térmico, estrutural, bem como segurança, economia e demais questões. Mais do que o uso de um computador para auxiliar na tarefa de desenhar, programar modifica profundamente as relações entre o designer e seu produto, seja um mouse ou um edifício, modifica a maneira como projetamos de uma maneira geral. Programação até então era compreendida como assunto para especialistas. Não fazia parte, e não faz, da educação básica de um designer ou de um arquiteto, mas é elemento do ciclo básico dos cursos de engenharia (Burry, 2011). Os professores e alunos de nossa escola não conheciam os conceitos de script aplicados ao processo projetual do arquiteto ou designer. Apresentou-se inicialmente a possibilidade de facilitar as tarefas repetitivas e gradualmente demonstrou-se que o script pode ser uma nova maneira de contribuir no processo de trabalho como ferramenta que potencializa a análise de dados necessários ao projeto.

Devemos levar em conta que o ensino de sistemas de informação, não somente em nossa instituição mas na grande maioria das escolas dearquitetura edesign brasileiras, possuem outras prioridades que não apresentar os conceitos básicos dos sistemas de informação que utilizamos. A universidade, como um espaço que favoreça o pensamento livre na área de digital design, é muitas vezes coagida a colocar o foco em ensinar ferramentas e habilidades práticas, de aplicação imediata, tal como o desenho bidimensional, renderizações foto-realísticas, detalhamento de partes da construção, referenciamento, composição de tabelas, memorandos e demais elementos que estão alheios a uma nova possibilidade projetual e que, sem dúvida, deve ser levada em consideração. Tão logo, com tais prioridades, os sistemas de informação e comunicação aplicados ao design e arquitetura estão sempre carentes de cognição e estudos mais aprofundados de suas potencialidades, pois as grandes maiorias dos profissionais de arquitetura no Brasil não geram necessariamente uma relação direta entre o objeto modelado tridimensionalmente e o fluxo de informações necessárias a sua documentação, construção, fabricação de componentes, cronograma de montagem na obra e manutenção do edifício depois de construído. O modelo tridimensional esta desconectado das informações inerentes ao projeto no fluxo de trabalho do arquiteto comum, sendo necessárias alterações manuais e pontuais em toda a cadeia de dados do projeto quando necessárias modificações.

Uma vez apresentada a razão pela qual podemos utilizar o script como parte de nosso processo projetual, passouse a apresentar os alunos à prática de tais técnicas, e foram disponibilizadas aulas extras, em formato de Workshops, nos laboratórios de informática da própria escola, oferecendo aos alunos abatimento de sua carga de horas de atividades complementares. Utilizando uma base virtual com vídeo aulas em português e divulgadas por redes sociais além do próprio site da escola, houveram também diversos encontros presenciais envolvendo a utilização dos softwares Ecotect, Rhinoceros, e seu modelador paramétrico Grasshopper com os plug ins Kangaroo, Weaverbird, Geco e Mesh +. Os alunos integraram tais atividades complementares e adquiriram treinamento básico, sendo apresentados ao universo do projeto auxiliado por algoritmo.

\section{Frente 02: Teoria e projeto na era digital.}

Além da importância de apresentar as ferramentas de trabalho aos alunos, não poderiam deixar de ser apresentados também, certos conceitos e noções relacionados a novos quadros teóricos extremamente importantes para compreensão do processo digital de projeto. Tão logo, a bibliografia pertinente ao assunto deveria ser explorada, mas de maneira superficial. Embora alguns estudantes tenham interesse na pesquisa acadêmica, é notório o desinteresse da grande parte dos alunos em adquirir conhecimentos teóricos, principalmente tratando-se de uma atividade extra que não seria cobrada via exames ou aprovações em disciplinas específicas.

A estratégia adotada foi mesclar as atividades. As presenciais ocorriam no laboratório de informática, onde estavam instaladas as ferramentas, porém os assuntos eram mesclados: em algumas aulas, aplicavam-se apenas estudos práticos; em outras, iniciava-se com assunto prático, e conduzia-se o desenrolar da aula para slides com obras emblemáticas e tópicos relevantes de estudos de pesquisadores como Rivka Oxman, Willian Mitchel, Branko Kolarevic e John Frazer, sempre fazendo menção a alguma bibliografia de apoio. Desta forma, conseguiu-se apresentar 
conceitos fundamentais a todos os alunos que participavam das atividades, mesmo aos que não estavam envolvidos em Iniciação Científica e trabalhando diretamente o assunto. Um grupo maior de alunos tomou conhecimento de que existem muitos outros elementos além do software e que são necessárias novas maneiras de raciocinar que vão além das telas dos computadores.

Pareceu adequado iniciar a apresentação dos conceitos que formam o quadro teórico base para a arquitetura e design digitais a partir da modificação social que as tecnologias da informação e comunicação suscitaram, que tais mudanças não deviam se restringir a maneira como nos comunicamos, mas que afetariam diversos campos do conhecimento e que os processos projetuais não estariam de fora deste quadro. Especialmente falando da virada do século XX para XXI, devemos ressaltar inovações no campo das ciências da comunicação e informação, que influenciaram a maneira como organizamos nossos dados. Nicholas Negroponte apontou no livro "Being Digital" a ideia da substituição do átomo para o bit. Neste conceito, percebemos a desintegração da informação em relação ao suporte. Antes da rede que interliga nossos computadores, a informação estava inserida em um suporte constituído por um elemento físico indissociável. $\mathrm{Na}$ era digital a informação separou-se do suporte: posso acessar a mesma informação, mas com suportes diferentes, como meu notebook, desktop, celular ou tablete.

Neste ponto, passou-se a conduzir os alunos a partir de uma pergunta base: Quais as consequências para o designer e arquiteto neste processo como um todo? Será que se pensarmos design, como um processo de materialização de um conjunto de informações em um objeto físico, até que ponto a desmaterialização da informação, de átomo para bit, modifica efetivamente a maneira como projetamos nossos produtos e edifícios? A nova classe de edifícios e produtos que surgiu na era digital constitui uma classe única de objetos (segundo Rivka Oxman 2006), o que nos leva a acreditar que o design digital é um fenômeno capaz de modificar a maneira como projetamos e fabricamos, a ponto de causar o mesmo furor que causou o Movimento Moderno do início do século $\mathrm{XX}$ em termos conceituais.

Em Dezembro de 1995, John Frazer escreveu um texto intitulado "The Architectural Relevence of Cyberspace" que abordava as relações entre a arquitetura e linhas de raciocínio derivadas de novas tecnologias. Frazer nos mostrou como uma nova consciência emergiu com profundas implicações para a arquitetura e o design. Segundo Frazer, a internet é um mundo paralelo ao nosso compreendido no que ele conceituou como ciberespaço, sustentado pela existência de computadores interligados, que abrigam a manifestação de profundas modificações culturais e tecnológicas, que foram capazes de reformular nossas visões do mundo a partir de meados da década de 1990. Mudou nossa percepção das coisas onde trocamos nossa percepção de um universo de objetos, para focar-nos nas relações entre tais objetos, que é a característica mais paradigmática da mudança de cenário na virada do século XX para XXI. O mais importante passou a ser o processo, e não o objeto, e por diversas razões. O novo século é descentralizado, dessincronizado, diverso, simultâneo, anárquico, customizado e as chaves conceituais para tais mudanças são a informação, sustentabilidade, participação e demais propriedades emergentes. Estes fenômenos constituem uma mudança social e tecnológica trabalhando para a reversão de nossas decisões, inclusive políticas. Devemos ressaltar que tais mudanças paradigmáticas estão não apenas na maneira como enxergamos o futuro, mas como olhamos e compreendemos nosso passado.

Ao migrarmos de átomos para bits e interligarmos nossos sistemas de processamento de dados através da internet, democratizamos o acesso à informação. Com o incremento da capacidade de transmitir mais bits por segundo, a cada novo dia, as vantagens em distribuir a informação pelo mundo possibilitou que não fossemos apenas receptores, mas também nos colocou como emissores de informação, graças aos constantes desdobramentos do aumento no trânsito de bits. Desta forma, reforçamos a coexistência de uma nova Inteligência Coletiva, que Cristopher Hight e Chris Perry apresentaram na edição de outubro de 2006 da revista AD. Nesta mesma edição os autores citam Pierre Levy, que trabalhou o mesmo conceito, ampliando seu sentido não apenas como um objeto cognitivo, mas para além da compreensão de seu senso etimológico de junção, de proximidade, como unindo não apenas ideias, mas pessoas e construindo uma sociedade. A colaboração não emerge de dois autores, isolados em uma voz uníssona, e sim ligada à ideia da proliferação que cria o coro de uma multidão. Se analisarmos o fenômeno da internet, e seus efeitos mediante uma população cada vez mais plugada, a distribuição de informações pelo globo, perfeitamente pode modificar uma série de atividades humanas, inclusive o design e a arquitetura.

Tal fluxo de informação possibilitou o estreitamento entre as disciplinas: a transdisiplinaridade é uma característica das novas sociedades baseadas no trânsito de informação. Por este prisma, a ligação entre informática, telecomunicações e novas organizações sociais, políticas e econômicas sugerem que a tradicional divisão nas áreas do design, que ocorreu nos séculos anteriores, e que colocaram as habilidades de quem constrói e de quem concebe em profissões distintas, tende a desaparecer, e serem substituída por diferentes organizações de conhecimento e prática. $O$ intercâmbio interdisciplinar de práticas descentralizadas emergiu para reposicionar e fornecer um novo ferramental para os profissionais de arquitetura e design, de forma a engajá-los na solução de problemas não convencionais, questões complexas das forças do local, questões inerentes à sustentabilidade e processos de manufatura digital.

Marshall McLuhan já chamava a atenção, desde a década de 1960, para o surgimento de novos organismos sociais, baseados nos princípios de descentralização e coletividade. Em partes McLuhan, que se embasava nas já disponíveis novidades das telecomunicações, comentava 
sobre o surgimento de uma "vila global". As tecnologias de comunicação e informação não apenas ampliaram ordens sociais pré-existentes, mas potencializaram a capacidade humana de raciocínio, com modos autômatos de produção e isso acarretou mudanças paradigmáticas profundas, que acaloram debates há pelo menos 50 anos, desde o início da discussão de revisões de processos da década de 1960.

O conceito global apontado nas ideias acima, não pode ser tomado como algo novo. Buckiminster Fuller já aspirava por uma visão globalizada das informações, que associava a realização técnica de um ciberespaço com a simultânea desmaterialização dos meios de comunicação global, tendo impacto direto sobre nosso entorno físico e suas relações como nossos mundos. Ainda de acordo com Frazer, a rede eletrônica de informações é heterogênea, independente do seu local, informal, ativa e em uma análise rasa, podemos observar que é exatamente o oposto do que encontramos na arquitetura tradicional, e isso nos leva a imaginar a morte das cidades como as conhecemos de tal forma a compreender que a simbólica função da nova arquitetura é tornar visíveis nossos edifícios: não somente como monumento a expressões formais de sua função, mas como parte essencial de sua função. A arquitetura como um órgão essencial de interação com o seu entorno, alternando tanto a recepção como a transmissão de informações.

Remontando conceitos presentes em outro trabalho de John Frazer, "A Natural Model for Architecture. The nature of evolutionary body", a nova arquitetura e design emergentes dos tempos atuais, devem ser subprodutos concebidos no âmbito de uma comunidade mundial, baseada na cooperação global, envolvendo ideias de responsabilidade ecológica e social, usando a computação como um acelerador evolucionário. A ênfase mudou do produto para o processo tal como Buckiminter Fuller, John Cage e Marshall McLuhan já haviam salientado em seus estudos. Mudou das formas para as relações entre as formas, das formas e seu entorno e das formas e suas relações com seus usuários. Este novo modelo irá modificar nosso entendimento e interpretação da arquitetura do passado, e certamente irá modificar nosso conceito de novo. Com tantas variáveis disponíveis para inserirmos em nossos projetos, somente utilizando ferramentas digitais, seriamos capazes de concebermos edifícios e produtos capazes de darem uma resposta a estas novas questões de alta complexidade.

Novas formas de projetar, geralmente seguem acompanhadas, ou precedendo, novas formas de construir. Devemos destacar o desenvolvimento de sistemas de fabricação controlados por computador, os sistemas CNC (controle numérico computadorizado pelo IMT em 1951) bem como a popularização do uso dos computadores nas décadas de 1980 e 1990, que aceleraram a maneira como arquitetos e designers relacionavam-se com os meios digitais.

Com tais avanços na utilização de meios digitais, tanto para fase conceitual, como nas etapas de fabricação dos produtos de uma maneira geral, gerou-se uma nova classe de objetos, e no campo da construção civil, as modificações apresentam-se profundas e abriram novas linhas de pensamento, que revisam as relações entre o arquiteto e seu edifício, que vão desde o papel do desenho dentro de uma nova realidade produtiva, onde as construções de edificações são gerenciadas por informações digitalizadas, e a postura projetual que o arquiteto deve assumir face tais inovações tecnológicas. Avaliando o trabalho de Branko Kolarevic, pode-se afirmar que há uma nova classe de edifícios sendo produzidos no período classificado como a "era digital". Poder-se-ia aqui, ainda embalado no seu raciocínio, pensar que o elemento central e comum a esta nova classe de produtos é o fato que as novas técnicas estão possibilitando a conexão direta entre o que pode ser projetado, e como pode ser construído, trazendo à tona o aspecto primordial do significado da informação, influenciando a produção, a comunicação, a aplicação e o controle da indústria da construção civil de uma maneira geral.

O que nos chama a atenção em especial neste processo apontado por Kolarevic é a maneira como a integração entre concepção e construção/fabricação são extremamente diferentes do queestamosacostumados noprocessotradicional de projetar. Geralmente devemos preparar desenhos, que serão materializados em um canteiro de obras, após serem interpretados por pedreiros, carpinteiros e todo um exército de mão de obra corriqueiramente de baixa qualificação. Neste processo o arquiteto ocupa a posição de um profissional que prepara tais desenhos. Apenas. Este papel diluiu a posição do arquiteto, que em eras anteriores, ocupava o papel do mestre da obra, associando a execução e criação em um único meio. Não eram necessários desenhos para orientar o trabalho de esculpir blocos de pedra ou outros materiais. Desenhava-se diretamente no material. O desenho agora possui um novo papel: é elemento que conduz a geração de um G Code, que alimenta o sistema de fabricação adotado, traduzindo em materialidade, todos os elementos tidos como virtuais nas telas de nossos computadores. Devido ao grau de complexidade das peças geradas, é necessário que a montagem das peças siga as instruções, que estão presentes na tela do mesmo computador, integrando o meio digital desde a concepção, a fabricação e a montagem dos sistemas desenvolvidos.

Para um sistema de informação, a materialidade é um dado. E como tal, é um elemento do mundo virtual. O processamento da informação é um sistema virtual. Já a fabricação, seja de qualquer elemento, por métodos completamente manuais ou utilizando máquina mecânica é ligado à materialidade, ao mundo real. Máquinas controladas por computador conseguem associar estes dois mundos distintos e as consequências para os envolvidos na fabricação de objetos (mesmo um edifício) são muitas.

Para complementar as aulas práticas (e práticas/teóricas) nos laboratórios foram convidados profissionais que de longa data trabalham o assunto. Franklin Lee, Afonso Orciuoli, Eduardo Sampaio Nardelli e Anne Save foram convidados a prestigiar o projeto, proferindo palestras no auditório da escola. Com a vinda de profissionais não vinculados à nossa escola, os 
alunos e colegas professores puderam tomar conhecimento de que é necessário um novo quadro teórico para compreensão correta das novas obras que tem surgido nos últimos 20 anos, e que para montagem de tal quadro se faz necessário novas pesquisas. (Oxman, 2006).

\section{Frente 03: Fabricação digital e modelagem paramétrica.}

Logo após a inauguração do Laboratório foi firmada uma parceria com a empresa Masisa, que forneceu chapas e os ensaios do recém-lançado MDF resistente à água, a partir de então a proposta de um projeto para um abrigo responsivo, a ser montado em área de propriedade da escola, foi lançada. Após a coleta dos dados iniciais, os alunos que participaram das etapas anteriores, orientados pelo professor responsável, iniciaram um processo de trabalho $100 \%$ digital, utilizando as ferramentas e bases conceituais que tomaram conhecimento no semestre anterior e criaram uma série de algoritmos possíveis à solução do problema.

Devido à natureza do material e os dados técnicos obtidos com os ensaios laboratoriais fornecidos pela empresa, uma das premissas do projeto era a adoção de uma geometria que fosse capaz de absorver e distribuir bem esforços de compressão e minimizar esforços de tração, sem necessariamente adotar formas ortogonais, que dificultariam a relação do volume a ser edificado em harmonia com as forças do lugar, como insolação, sombreamento, ventos e demais parâmetros, uma vez que os algoritmos desenvolvidos sugeriam uma melhor adaptação de um objeto que possuísse formas orgânicas.

Para equacionar o problema da forma necessária com o material disponível, a partir da leitura do material de Arturo Tedeschi "Algorithm Aided Design - Parametric architecture with Grasshopper" partiu-se à compreensão mais clara de processos de trabalho que não utilizavam o desenho como elemento principal do processo de trabalho. Foram estudadas as obras de arquitetos como Luigi Moretti, Frei Otto e Anthony Gaudi.

Os alunos descobriram (e os professores aprofundaram) a maneira peculiar como estes profissionais conduziam suas pesquisas utilizando técnicas de "Form Finding", onde a força da gravidade e o próprio comportamento dos materiais eram elementos que definiam a forma do objeto de estudo. Destes arquitetos, o que realmente influenciou o grupo de alunos foi o trabalho de Gaudi, especificamente o uso que ele fez do arco catenário em seu projeto da "Sagrada Família". Nota-se que em arcos catenários as deformações ocorrem, em sua quase totalidade, por compressão. Esta característica também foi observada na obra do engenheiro uruguaio Eladio Dieste, que empregava com grande destreza o uso de materiais como tijolos, que assim como as placas de MDF, são excelentes materiais quando submetidos a tais esforços.

Definida a necessidade de compreender melhor o arco catenário, orientou-se uma pesquisa mais atenta ao assunto, procurando compreender as funções matemáticas que geram tais curvas, bem como as diferenças básicas entre diferentes tipos de arcos e suas propriedades estruturais. Traduzindo em experiência prática os conhecimentos de "Form Finding" observados nos estudos acima descritos foi tomada uma direção digital para testar tais possibilidades. Notório pela versatilidade, e facilidade no uso, o plug-in para Grasshopper "Kangaroo" foi escolhido como acelerador de partículas.

Como o trabalho ainda encontra-se em desenvolvimento, o que conseguiu-se produzir até o momento foram arcos catenários construídos digitalmente e utilizando-se MDF. Estas atividades serviram como testes de assertividade, tanto do processo digital de trabalho como para testar o carregamento das estruturas produzidas. Atualmente estão sendo desenvolvidos, no Laboratório de Fabricação Digital da escola, protótipos para uma cúpula, a partir de arcos catenários, baseando-se nos abrigos da tribo Musgum, do norte do Camarões.

Para a produção dos arcos foram necessárias diversas reuniões para definições dos algoritmos mais adequados. Ao optarmos pelo uso do Kangaroo, a modelagem base teve que ser toda em meshes, o que de fato favoreceu o preparo de modelos para fabricação digital já que estas não possuíam dupla curvatura quando geradas, o que otimizava o processo de usinagem sensivelmente no tocante a tempo de trabalho.

Com o apoio dos equipamentos do laboratório, que possui técnicas de fabricação digital por adição (impressoras 3d Makerbot que utilizam PLA ou ABS) e técnicas de subtração (máquina de corte a laser e router $\mathrm{CNC}$ ), os alunos tiveram a possibilidade de criar modelos físicos, tanto em escala reduzida como em escala um para um, sempre que algum algoritmo criado gerasse algum resultado razoável, o que ampliou as possibilidades de interação com os objetos criados virtualmente, contribuindo sensivelmente com a agilidade nas tomadas de decisão, devido a alta fidelidade e precisão que tais técnicas oferecem.

\section{Resultados}

Em linhas gerais, podemos destacar diversas observações que, na etapa do desenvolvimento desta pesquisa, aparecem aqui como conclusivas. A ideia de desenhar sobre o material, que indiretamente sugere o processo de projeto adotado, levou o grupo a modificações na condução de decisões em tempo real, em função de sistemas de encaixe entre peças e problemas construtivos diversos que em processos analógicos de trabalho apresentam-se como implícitos, mas dentro de um fluxo digital de projeto e fabricação, utilizando modelagem paramétrica e prototipagem rápida, aparecem como explícitos e demandam imediata solução. Embora a atividade ainda esteja em andamento, como mencionado, pode-se notar que a aplicação do pensamento digital sobre o projeto dinamiza a relação entre o arquiteto ou designer e seu objeto, agilizando e aprimorando sensivelmente os caminhos a serem tomados durante o processo projetual, entregando altíssima qualidade.

Do ponto de vista acadêmico, a experiência tem mostrado que há um custo inicial para compreender e aplicar as novas formas digitais de projetar, devido à escassa 
bibliografia em língua portuguesa, poucos interlocutores nacionais, as diversas críticas de colegas contrários às novas técnicas, que culminam em uma rarefeita massa crítica que de suporte e agilize a troca de informações necessárias à condução de experiências desta natureza, mas mesmo assim, a conta parcial desta questão tem provado ser favorável aos meios digitais aplicados em arquitetura e design, de acordo com o grupo. Esta atividade de extensão tem gerado, embora de forma lenta, a sensibilização da comunidade do Centro Universitário Belas Artes de São Paulo ao assunto digital, e este resultado é muito animador. A fabricação de protótipos em escala natural permite a todos da escola visualizarem as experiências do grupo, atraindo novos alunos e professores de todas as áreas de conhecimento da instituição.

Sob o âmbito técnico, especificamente do ponto de vista da fabricação digital e uso de softwares, observamos que o trabalho só pode ser realizado com o conhecimento disponível pelo grupo devido à utilização do plug-in Kangaroo combinado ao Weaverbird. As formas geradas em diversos algoritmos criados pelos alunos resultavam em superfícies com dupla curvatura, que seriam posteriormente entendidas como partes a serem usinadas pelo router, uma vez que a escola disponibilizou o software V Carve, responsável pela criação de Gcodes para controle dos movimentos de nossa router $\mathrm{CNC}$. Com a combinação destas ferramentas, o grupo criou geometrias que puderam ser divididas em seguimentos planos, e assim adequando o projeto a suas variáveis imediatas, que é a utilização de placas de MDF em sistemas de fabricação digital com router.

\section{Acknowledgments}

We thank to the SIGraDi Executive International Committee for providing the basis of this formatting style.

\section{References}

OXMAN, Rivka, (2006) Theory and Design in the First Digital Age, IN Design Studies, Vol 27, May 2006, P 229-247

MITCHELL, William J. Constructing Complexity: Computer Aided Architectural Design Futures 2005: Proceedings of the 11th International CAAD Futures Conference held at the Vienna University of Technology, Vienna, Austria, on June 20-22, 2005. Springer, Netherlands, 2005

TEDESCHI, Arturo. AAD_Algorithms Aided Design. Parametric Strategies using Grasshopper. Edizioni Le Penseur, Rome, 2014.

FRAZER, John. (2013) The Architectural Relevance of Cyberspace. The Digital Turn in Architecture 1992-2012. John Wiley and Sons Ltd.

BURRY, Mark. Scripiting Cultures: Architecturel design and programming. Londres, 2013, John Wiley and Sons Ltd.

KOLAREVIC, Branko. Architecture in the digital age: design and manufacturing. Spon Press, New York, 2003.

NEGROPONTE, Nicholas. Being Digital. First Vintage Books Edition. New York, 1995. 